\title{
EXTRAÇÃO E EXPORTAÇÃO DE MACRONUTRIENTES POR FRUTOS DE GUA- RANÁ (Paullinia cupana var. sorbilis) NO MUNICÍPIO DE MAUÉS - AM*
}

\author{
ANTONIO MARIA G. DE CASTRO** \\ JOSÉ RENATO SARRUGE *** \\ ORLANDO CAMPELO RIBEIRO****
}

\section{RESUMO}

Foram analisados frutos de guaraná (Paullinia cupana var. sorbilis) provenientes de três propriedades do município de Maués - AM, objetivando determinar as quantidades de macronutrientes extraídas e exportadas pelos frutos de guaraná. Constituiu-se 4 amostras compostas de frutos, representando dois locais adubados e dois locais não adubados, nas três propriedades escolhidas.

Constatou-se maior exigência pelo $\mathrm{N}$ e pelo $\mathrm{K}$. Para cada produção de $100 \mathrm{~kg}$ de frutos (matéria seca), são aproximadamente $2,71 \mathrm{~kg}$ de $\mathrm{N}$; $0,18 \mathrm{~kg}$ de $\mathrm{P} ; 0,95 \mathrm{~kg}$ de $\mathrm{K} ; 0,10 \mathrm{~kg}$ de $\mathrm{Ca} ; 0,13 \mathrm{~kg}$ de $\mathrm{Mg}$ e $0,10 \mathrm{~kg}$ de $\mathrm{S}$. $\mathrm{O} \mathrm{N}$ e o $\mathrm{P}$, são elementos mais exportados pela produção, ambos apresentando o índice de $72 \%$ de exportação, seguidos pelo S (60\%), Mg (46\%), $\mathrm{K}(44 \%)$ e $\mathrm{Ca}(40 \%)$. A devolução da polpa dos frutos ao guaranazal é recomendado, devido ao seu conteúdo de macronutrientes.

\section{INTRODUÇÃO}

O guaraná (Paullinia cupana var. sorbilis (Mart.) Ducke) é cultivada em escala comercial principalmente no município de Maués - Amazonas, sendo de grande importância econômica para a região.

A cultura é conduzida em bases empíricas, em face a pouca disponibilidade de dados técnicos. CASTRO (1971) aponta a falta de pesquisas como um dos fatores relacionados as baixas produções conseguidas produtores, em média $0,33 \mathrm{~kg} /$ pé $/$ ano de amendoas torradas.

Um dos meios de se conseguir o aumento da produtividade da cultura será através da nutrição mineral. As referências existentes sobre a nutrição do guaranazeiro são mínimas, inexistindo dados a respeito da extração e exportação de nutrientes pela cultura. Estes dados podem dar uma idéia das necessidades de macronutrientes do guaranazeiro e servirem de base para posteriores recomendações de adubação da cultura.

* Entregue para publicação em 30/12/1975. Trabalho realizado com parte dos dados da dissertação apresentada à E.S.A. "Luiz de Queiroz", para obtenção do título de Mestre do Engo Agro Antonio Maria G. de Castro.

* Assessor Técnico da ACAR-Amazonas. Bolsista do CNPq.

*** Professor do Departamen to de Química da E.S.A. "Luiz de Queiroz".

*** Assessor Técnico da ACAR-Amazonas. 
Em função da deficiência de dados sobre a extração e exportação de macronutrientes pelo guaranazeiro, foi realizado o presente trabalho, com os seguintes objetivos:

- Determinar a extração de macronutrientes pela produção total de frutos de guaraná, em condiçôes atuais de cultivo no município de Maués - AM.

-.. Determinar as quantidades de macronutrientes exportados pela produção, em idênticas condiçōes.

\section{MATERIAIS E MÉTODOS}

Em três propriedades do município de Maués - AM, escolhidas para um levantamento de estado nutricional da cultura, foram escolhidas duas áreas cujas plantas haviam recebido uma adubação química e duas áreas que nunca haviam sido adubadas. Em cada uma das áreas foi coletada uma amostra composta de frutos, durante o período de outubro-dezembro de 1974, época de duração da safra de guaraná.

Após a coleta, os frutos foram separados em polpa e sementes e secos inicialmente ao sol e posteriormente em estufa de circulação forçada de ar, a 700C.

Após a secagem, as amostras foram moídas em moinho Wiley, peneira nọ 20, e analisadas quimicamente para $\mathrm{N}, \mathrm{P}, \mathrm{K}, \mathrm{Ca}, \mathrm{Mg}$ e S, segundo os métodos descritos por SARRUGE \& HAAG (1974).

\section{RESULTADOS E DISCUSSÄO}

Os frutos de guaraná são compostos de uma polpa de revestimento da semente, composta pela casca e pelo arilo, e pela semente, composta de tegumento e amendoa. Botanicamente foi descrito por CORREIA (1952) da seguinte forma: "fruto cápsula longo estipitada, piriforme, elíptica, septicida, trilocular, 6 a $8 \mathrm{~mm}$ de comprimento e $10 \mathrm{~mm}$ de diâmetro, quase preta quando seca, glabra externamente, contendo uma ou duas sementes ovóides, glabras, arilo curto e cupuliforme, branco".

São as sementes que possuem valor comercial, sendo que estas quando torradas recebem a denominação de "guaraná em rama". MARAVALHAS (1965) considera que as "cascas" (tegumento) das sementes devam ser também utilizadas, pois contém um teor de cafeína semelhante ao das amêndoas. Segundo o mesmo autor, as indústrias apenas utilizam as amêndoas, sendo os envoltórios (tegumentos) das mesmas desprezado. Entretanto, o aspecto de interesse para o presente tópico é determinar que partes dos frutos são exportados e que partes permanecem na propriedade, para calcular as quantidades de nut rientes exportados pelas colheitas.

Tradicionalmente, o guaraná é colhido manualmente, fruto por fruto e despolpado. As sementes são torradas, e sob a forma de guaraná em rama é comercializado (BRANDT et alii, 1973; WATZEL, 1938; MAIA, 1972). Uma parte da produção cada vez percentualmente menor (BRANDT et alii, 1973) é destinada a fabricação de bastões, ou pães de guaraná. Dessa forma considerando-se a comercialização de guaraná na forma 
de sementes, as amêndoas e tegumentos são exportadas, permanecendo a polpa nas propriedades, podendo ser reincorporadas ao solo.

No presente trabalho foram colhidas compostas de frutos das quatro propriedades, para se verificar empiricamente o efeito da nutrição no teor dos frutos e as quantidades de macronutrientes extraídas. Na Tabela 1, são apresentados os teores de macronutrientes na matéria seca das amêndoas (A), tegumentos $(\mathrm{T})$ e polpa $(\mathrm{P})$ de frutos de guaraná, das propriedades estudadas.

\begin{tabular}{|c|c|c|c|c|c|c|c|c|}
\hline & \multirow{2}{*}{ Local } & \multirow{2}{*}{$\begin{array}{l}\text { Parte dos } \\
\text { frutos }\end{array}$} & \multicolumn{6}{|c|}{ Teores de macronutrientes (\%) } \\
\hline & & & $\mathrm{N}$ & $\mathbf{P}$ & $\mathrm{K}$ & $\mathrm{Ca}$ & $\mathrm{Mg}$ & $\mathrm{S}$ \\
\hline \multirow[t]{3}{*}{ I } & (Bclém) & Amêndoa & 3,11 & 0,17 & 0,52 & 0,04 & 0,07 & 0,10 \\
\hline & & Tegumento & 2,79 & 0,11 & 0,85 & 0,19 & 0,15 & 0,12 \\
\hline & & Polpa & 3,04 & 0,17 & 1,82 & 0,22 & 0,19 & 0,12 \\
\hline \multirow[t]{3}{*}{ II } & (Desideri) & Amêndoa & 1,55 & 0,21 & 0,50 & 0,03 & 0,09 & 0,11 \\
\hline & Adubado & Tegumento & 2,91 & 0,12 & 0,65 & 0,18 & 0,19 & 0,12 \\
\hline & & Polpa & 2,56 & 0,19 & 1,77 & 0,22 & 0,23 & 0,13 \\
\hline \multirow[t]{3}{*}{ III } & (Magnani) & Amêndoa & 3,00 & 0,19 & 0,55 & 0,03 & 0,10 & 0.05 \\
\hline & Não Adubado & Tegumento & 2,88 & 0,14 & 0.67 & 0,13 & 0.16 & 0,17 \\
\hline & & Polpa & 2,62 & 0,18 & 2,05 & 0,22 & 0,26 & 0,17 \\
\hline \multirow[t]{3}{*}{ IV } & (Magnani) & Amêndoa & 2,88 & 0.20 & 0,59 & 0,04 & 0.12 & 0,11 \\
\hline & Adubado & Tegumento & 3.21 & 0,12 & 0,67 & 0,15 & 0,12 & 0,08 \\
\hline & & Polpa & 2,88 & 0,23 & 2,03 & 0,24 & 0,24 & 0,10 \\
\hline \multirow{3}{*}{\multicolumn{2}{|c|}{ Teores Médios }} & Amêndoa & 2,63 & 0,19 & 0,54 & 0,03 & 0,09 & 0,09 \\
\hline & & Tegumento & 2,95 & 0,12 & 0,71 & 0,16 & 0,15 & 0,10 \\
\hline & & Polpa & 2.77 & 0,19 & 1,92 & 0.22 & 0,23 & 0,13 \\
\hline
\end{tabular}

QUADRO 1 - Teores de macronutrientes nas partes dos frutos de guaraná em quatro locais no município de Maués-AM.

Como ocorreu nas folhas, o $\mathrm{N}$ apresentou os maiores teores nos frutos, seguido pelo K. Os outros macronutrientes apresentaram teores semelhantes.

Aparentemente não são notáveis as diferenças entre os teores nas propriedades adubadas e não adubadas. A amostragem utilizada não permitiu a análise estatística dos dados, para um maior aprofundamento, o que inclusive foge dos objetivos deste trabalho.

As amêndoas apresentaram teores semelhantes ao das folhas, no caso do N, P e S, e menores teores que as polpas para o K, Ca e Mig. Um fato notável são os baixos teores de $\mathrm{Ca}$ nas amêndoas.

Para o cálculo de extração de nutrientes, foram utilizados os valores médios, devido à semelhança entre os teores encontrados nas partes dos frutos, para os diferentes locais.

Inicialmente a matéria seca dos componentes dos frutos foram pesadas, para se determinar os percentuais de cada componente. Dessa forma para a matéria seca dos fru- 
tos das quatro propriedades, $58,78 \%$ correspondeu a amêndoa, $13,74 \%$ correspondeu ao tegumento e $27,48 \%$ correspondeu a polpa.

A partir desses números, e dos teores médios de macronutrientes da Tabela 1, calcularam-se as quantidades de nutrientes extraídas por $100 \mathrm{~kg}$ de frutos (amêndoas + tegumento + polpa), e que estão expressos na Tabela 2.

\begin{tabular}{lcccccc}
\hline \multirow{2}{*}{ Partes dos frutos } & \multicolumn{5}{c}{ Quantidades retiradas $(\mathrm{kg})$} \\
\cline { 2 - 7 } & $\mathrm{N}$ & $\mathrm{P}$ & $\mathrm{K}$ & $\mathrm{Ca}$ & $\mathrm{Mg}$ & $\mathrm{S}$ \\
\hline Amêndoas & 1,55 & 0,11 & 0,32 & 0,02 & 0,05 & 0,05 \\
Tegumentos & 0,40 & 0,02 & 0,10 & 0,02 & 002 & 0,01 \\
Polpa & 0,76 & 0,05 & 0,53 & 0,06 & 0,06 & 0,04 \\
Frutos (TOTAL) & 2,71 & 0,18 & 0,95 & 0,10 & 0,13 & 0.10
\end{tabular}

QUADRO 2 - Quantidades médias de macronutrientes extraídas por $100 \mathrm{~kg}$ de frutos de guaraná (matéria seca) em Maués-AM.

No totai, as maiores quantidades extraídas pelos frutos são de nitrogênio, o que confirma a exigência da cultura pelo elemento. Em seguida aparece o potássio, comı os outros elementos em plano inferior e semelhantes.

Pode-se inferir pela Tabela 2 que, através da comercialização de guaraná em rama (amêndoa + tegumento), aproximadamente $72 \%$ do N, $72 \%$ do $\mathrm{P}, 44 \%$ do $\mathrm{K}, 40 \%$ do $\mathrm{Ca}, 46 \%$ do $\mathrm{Mg}$ e $60 \%$ do $\mathrm{S}$ extraídos pelos frutos estão sendo expertados, permanecendo o restante na propriedade. Este aspecto reforça a necessidade das reposições, principalmente de $\mathrm{N}$ e $\mathrm{P}$, que são os macronutrientes exportados em maior quantidade.

$\mathrm{Na}$ metodologia analítica empregada, as sementes foram secas em estufa a semelhança do processo de torração, podendo-se extrapolar os dados de extração e exportação para o guaraná em rama, com pouca margem de erro. Entretanto, na necessidade de extrapolar os cálculos presentes para a produção de sementes frescas, pode-se fazer as correções baseadas no índice de umidade calculade a partir dos resultados de MAIA (1972), correspondente a aproximadamente $50 \%$ de umidade nas sementes verdes.

Finalmente, pode-se estimar as quantidades de macronutrientes exportados por ha, através da produtividade calculada a partir da produção média por pé, e de uma densidade média de plantio de 300 plantas per ha.

A Tabela 3 apresenta uma estimativa das quantidades de macronutrientes exportadas por hectare, em cada uma das propriedades do levantamento, pela cultura do guaraná.

$\mathrm{O} N$ é o nutriente exportado em maior quantidade, seguido do $\mathrm{K}$. Vale ressaltar as pequenas quantidades de nutrientes exportadas pela produção. 


\begin{tabular}{|c|c|c|c|c|c|c|c|c|}
\hline & \multirow{2}{*}{ Locais } & \multirow{2}{*}{$\begin{array}{l}\text { Produtividade } \\
\mathrm{kg} / \mathrm{ha}\end{array}$} & \multicolumn{6}{|c|}{$\begin{array}{l}\text { Quantidades exportadas pelas sementes } \\
\qquad(\mathrm{kg} / \mathrm{ha})\end{array}$} \\
\hline & & & $\mathrm{N}$ & $P$ & K & $\mathrm{Ca}$ & $\mathrm{Mg}$ & S \\
\hline I & $\begin{array}{l}\text { Belém } \\
\text { (Não Adubado) }\end{array}$ & 186,00 & 3,63 & 0,24 & 0,78 & 0,07 & 0,13 & 0,11 \\
\hline II & $\begin{array}{l}\text { Desideri } \\
\text { (Adubado) }\end{array}$ & 90,00 & 1,75 & 0,12 & 0,38 & 0,04 & 0,06 & 0,05 \\
\hline III & $\begin{array}{l}\text { Magnani } \\
\text { (Não Adubado) }\end{array}$ & 267,00 & 5,21 & 0,35 & 1,12 & 0,11 & 0,19 & 0,16 \\
\hline IV & $\begin{array}{l}\text { Magnani } \\
\text { (Adubado) }\end{array}$ & 237,00 & 4,62 & 0.31 & 0,99 & 0,09 & 0,16 & 0,14 \\
\hline
\end{tabular}

QUADRO 3 - Exportação de macronutrientes pela cultura de guaraná (sementes) em $\mathrm{kg} / \mathrm{ha}$, em quatro propriedades do Município de Maués-AM.

A baixa disponibilidade de nutrientes nos solos de cultivo, provavelmente deverá estar associada as baixas exportações de macronutrientes e conseqüentemente as baixas produtividades. Entretanto, dentro do atual contexto, as pequenas quantidades de nutrientes exportadas pelas produções de guaraná, mesmo um regime de alternância das produções, pode explicar a continuidade do cultivo em solos com um nível tão baixo de disponibilidade de nutrientes.

\section{CONCLUSÃO}

- A matéria seca de $100 \mathrm{~kg}$ de frutos contém aproximadamente $2,71 \mathrm{~kg}$ de $\mathrm{N} ; 0,18$ $\mathrm{kg}$ de $\mathrm{P} ; 0,95 \mathrm{~kg}$ de $\mathrm{K} ; 0,10 \mathrm{~kg}$ de $\mathrm{Ca} ; 0,13 \mathrm{~kg}$ de $\mathrm{Mg}$ e $0,10 \mathrm{~kg}$ de $\mathrm{S}$.

- A planta é mais exigente em $\mathrm{N}$ e $\mathrm{K}$.

-- Das quantidades de macronutrientes extraídas, são exportados pelas sementes (amêndoas mais tegumentos) aproximadamente $72 \%$ do N, $72 \%$ do P, 44\% do K, $40 \%$ do $\mathrm{Ca}, 46 \%$ do $\mathrm{Mg}$ e $60 \%$ do $\mathrm{S}$.

- A devolução da polpa dos frutos ao guaranazal deve ser estudada, em função da quantidade de macronutrientes que a mesma contém.

\section{SUMMARY}

\section{MACRONUTRIENTS EXTRATED AND EXPORTED BY GUARANÁ FRUITS (Paullinia cupana var. sorbilis) IN AMAZONAS STATE, BRAZIL}

Fruits of Guaraná (Paullinia cupana var. sorbilis) were chemically analized for $\mathrm{N}$, $\mathrm{P}, \mathrm{K}, \mathrm{Ca}, \mathrm{Mg}$ e S, with the purpose to determine the amount of macronutrient uptaked and exported by "guaraná" fruits. Four composed samples of fruits were colected from two groves fertilized and two unfertilized.

Nitrogen and $\mathrm{K}$ was the most absorbed elements by guarana fruits. $\mathrm{N}$ and $\mathrm{P}$ was the most exported elements. The return to the soil of fruit pulp is recomended. 


\section{LITERATURA CITADA}

BRANDT, S.A. et alii., 1973. Avaliação do mercado brasileiro de guaraná. Manaus, ACAR-Amazonas, 23 p. (Série Estudos, 1).

CASTRO, A.M.G. de, 1971. Diagnóstico da cultura do guaraná em Maués. Subsídios para o seu desenvolvimento. Manaus, ACAR-Amazonas, 34 p. (mimeog.).

CORREA, M.P., 1952. Dicionário das plantas úteis do Brasil. Rio de Janeiro, Serviço de Informação Agrícola, Ministério de Agricultura.

MAIA, A.L., 1972. O guaraná. Salvador. Associação dos Engenheiros-Agrônomos da Bahia, 14 p. (mimeog.).

MARAVALHAS, N., 1965. Estudos sobre o guaraná e outras plantas produtoras de cafeína. Manaus, INPA, 25 p. (publ. 10).

SARRUGE, J.R. \& HAAG, H.P., 1974. Análises químicas em plantas. Piracicaba, ESALQ, 56 p.

WATZEL, J., 1937. O guaraná, seu valor industrial e medicinal. Boletim do Ministério de Agricultura, 26(416):25-32. 